\title{
Dynamics in Buddhist Transfer in Eastern Central Asia 6th-14th Centuries: A Project Report
}

\section{BuddhistRoad Team*}

The ERC funded project BuddhistRoad aims to create a new framework to enable understanding of the complexities in the dynamics of cultural encounter and religious transfer in pre-modern Eastern Central Asia - the vast area extending from the Taklamakan Desert to North-east China. This region was the crossroads of ancient civilisations. Its uniqueness was determined by the complex dynamics of religious and cultural exchanges gravitating around an ancient communication artery known as the Silk Road. Buddhism was one major factor in this exchange; its transfer predetermined the transfer of adjacent aspects of culture, and, as such, the religious exchanges involved a variety of cultures and civilisations. These, in turn, were modified and shaped by their adoption of Buddhism. In many cases the spread of Buddhism overrode ethnic and linguistic boundaries in Eastern Central Asia creating a civilisational whole, which, despite its diversity, shared a set of common ideas originating from Buddhism. One specific aspect of this process in Eastern Central Asia was the rise of local forms of Buddhism. This project intends to investigate such Buddhist localisations and developments that took place between the 6th and the 14th centuries. At the core of the BuddhistRoad investigation are the areas of Khotan, Kucha, Turfan, Ganzhou, Dunhuang, as well as the territories of the Tangut and Khitan empires. The analysis will revolve around thematic clusters pertaining to doctrines, rituals and practices, the impact of non-Buddhist influences, patronage and legitimation strategies, sacred spaces and pilgrimages, and visual and material transfers.

Keywords: Buddhist transfer, Eastern Central Asia, Buddhism, cultural and religious exchange, Silk Road.

* Correspondence details: The BuddhistRoad Team includes Prof. Dr. Carmen Meinert (PI of ERC project BuddhistRoad, corresponding author), CERES, Ruhr-Universität Bochum, Universitätsstr. 90a, D-44789 Bochum, Deutschland: Email: carmen.meinert@rub.de; Dr. Henrik H. Sørensen (coordinator of ERC project BuddhistRoad), same address. Email: henrik.soerensen@rub.de; Dr. Erika Forte (research associate of ERC project BuddhistRoad), same address. Email: erika.forte@rub.de; Dr. Yukiyo Kasai (research associate of ERC project BuddhistRoad), same address. Email: yukiyo.kasai@rub.de. For further information on the project and the team members, please consult the project website: buddhistroad.ceres.rub.de/en/; for further information concerning the Center for Religious Studies (CERES), please consult the website of the institution: ceres.rub.de/en/. 


\section{Introduction}

The project »Dynamics in Buddhist Networks in Eastern Central Asia, 6th to 14th Centuries" (BuddhistRoad), funded by the European Research Council (ERC, 2017-2022), is being undertaken at the Center for Religious Studies (CERES) of the Ruhr-Universität Bochum (RUB). BuddhistRoad aims to understand the role of Eastern Central Asia in global and religious history through the dynamics of the adoption and spread of Buddhism in this region. Central Asia is scentrak to our understanding of global historical processes, despite the fact that its role in global history is still rather neglected. It is not only the missing link through which Eurasian or world history can be more fully understood, but it is also - as this project aims to establish - of major importance in religious history. This region was not simply a transition zone through which many of the world's cultural and religious achievements spread, where pilgrim monks, goods and ideas travelled from one civilisation to the other (be it India, Persia, China or Tibet), but is a place where all those civilisations connected and interacted through an ancient, local political-economic-cultural system that is often referred to as the sSilk Roads. ${ }^{1}$ The region of interest in the project is located at a geographical crossroads of ancient civilisations in the very heartland of the Eurasian continent, between the oasis of Khotan in the west and the Buddhist pilgrimage site Mount Wutai (in modern Shanxi Province, China) to the east (Fig. 1). Thus, it gravitates (if we move from west to east) around the areas of Khotan, the Uyghur Kingdoms (i.e. Turfan and Ganzhou), Dunhuang, the Tangut Kingdom (with Xingzhou and Kharakhoto) and the Khitan Empire (with the Buddhist pilgrimage site of Mount Wutai).

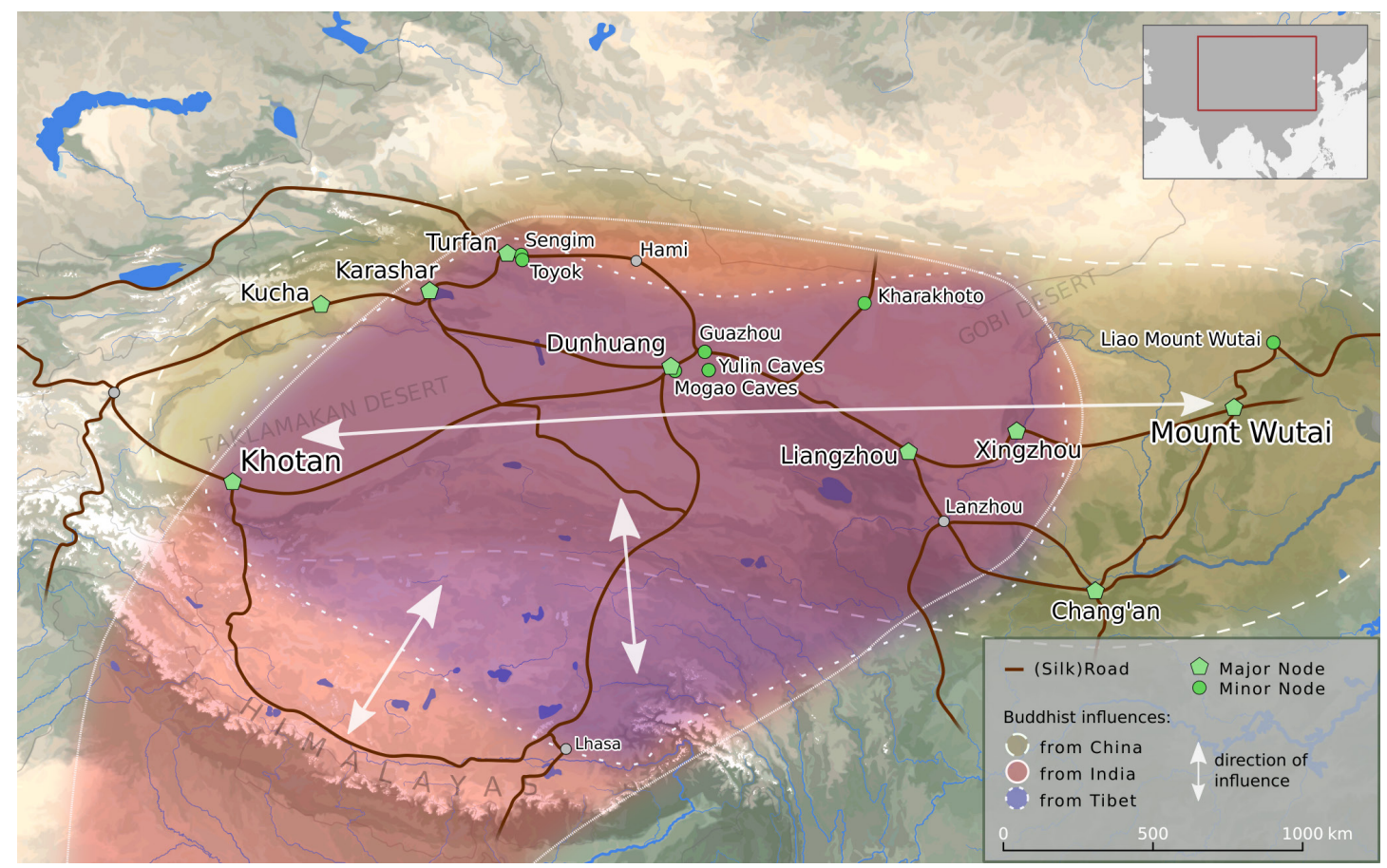

Fig. 1: Network of Buddhist nodes in Eastern Central Asia, by BuddhistRoad project 
Buddhism, which was most successfully transmitted for around 1500 years, both in and through this region, was the formative backbone of this vital region, where a multitude of ethnicities, languages, traditions, cults, and trends in material culture mingled together into a uniquely hybrid complex. This project proceeds from the hypothesis that the translocal spread of Buddhism developed into one of the driving forces in societal and cultural change of pan-Asian importance. In order to understand the Buddhist practices and beliefs, the religious dimension has to be extracted from the broader cultural patterns. One particular dimension of this translocal spread of Buddhism was the emergence of distinct local forms wherever the tradition became rooted.

The BuddhistRoad team proposes to examine the concepts of translocation and localisation, which represent complementary historical processes, and intends to trace its specific forms on the basis of the evidence that has been, and to a large extent is still to be recovered from the realms of material culture and textual and artistic heritage. Its aim is to investigate the interplay of external and internal dynamics in the unfolding of Buddhist localisations, and of the way in which translocal trends were processed at the local level and re-launched into the greater translocal system. Buddhism, which underwent often radical transformations under the influence of Central Asia's local cultures, thereby further influenced the mode of transmission to other cultural regions as well (e.g. Sinitic and Tibetan). In a nutshell: the project seeks to situate the many localisations that made up Eastern Central Asian Buddhism in the larger context of the spread of Buddhism in pre-modern Asia by looking at this region as an integrated whole rather than from the perspective of fragmented sub-disciplines. Thereby the project aims to create a new framework for enabling an understanding of (i) the dynamics of cultural encounter and (ii) Buddhist networks of transfer in the region during the pre-modern era. It is conceived of as a collaborative research project across disciplines (Archaeology, Art History, Buddhist Studies, History, Linguistics, Philology, Religious Studies, Ritual Studies) and Central Asian languages (Chinese, Khotanese, Old Uyghur, Tangut, Tibetan).

\section{Conceptual Outline}

In order to contextualise the Eastern Central Asian Buddhist localisations, the BuddhistRoad team choose to apply a network approach. This is helpful in order to move away from dated, territorial assumptions towards more relational, multiscale perspectives. The region in question was interconnected through a network of trade routes, along which a number of urbanised oases and Buddhist sacred sites emerged - under various dominions throughout the 6 th to 14 th centuries. In order to identify the primary points of importance in this system linking the oasis towns and sacred sites, there are locales, which carry added significance for a number or reasons. As is common to network approaches, broadly understood the term snetwork is being used in a broader metaphorical sense in order to understand how religious knowledge travels, finds local expression and at the same time remains interconnected among various locales. The project does not use the term in the sense of the social science method of network analysis. The locales are widely referred to as nodes, or points of relative import and significance (Fig 2). 

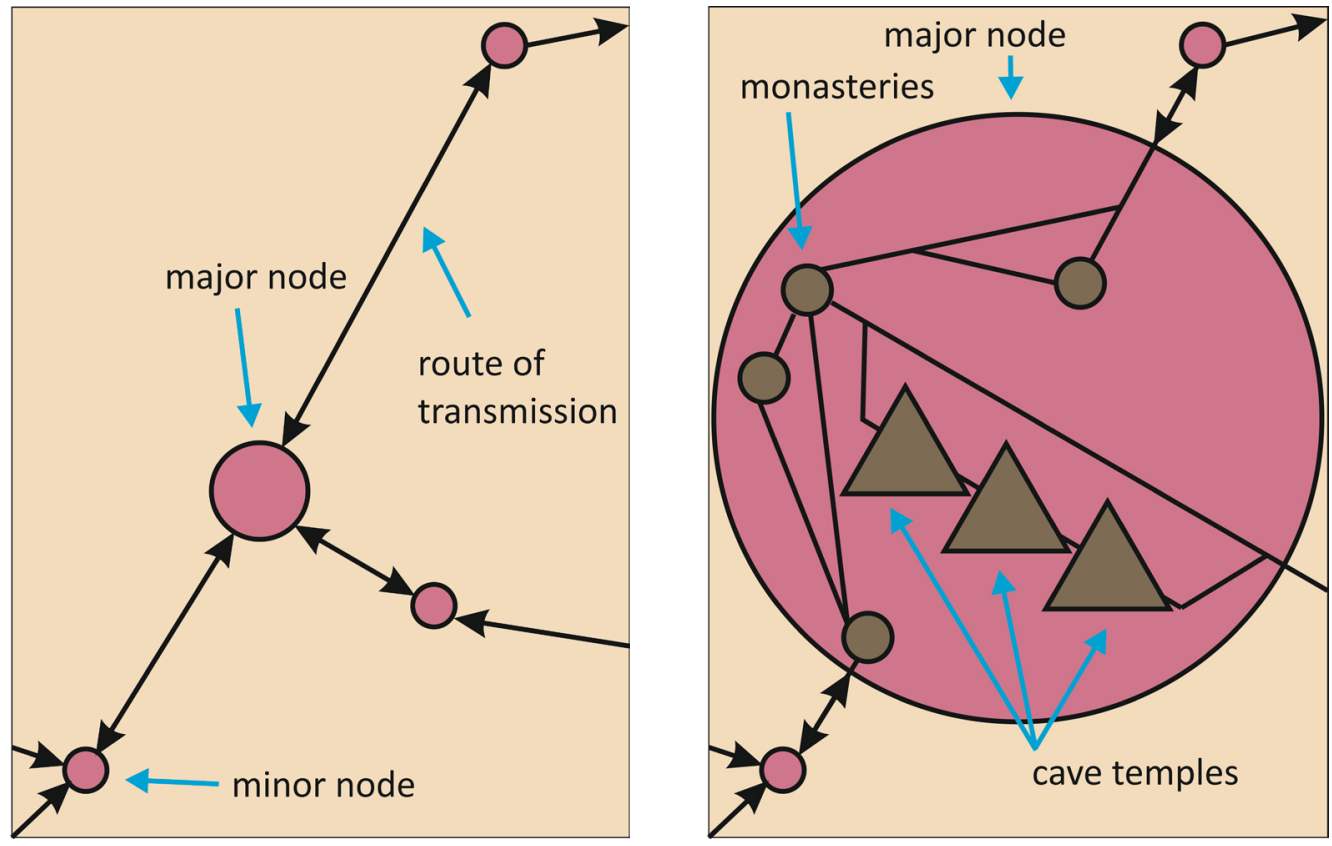

Fig. $2 a$ and b: Buddhist network with (a) model of transmission and (b) major node, by BuddhistRoad project

As such, >major nodes represent the generation of Buddhist impact on the surrounding area, where smaller centres, here described as 'minor nodes«, develop. The trade routes further connected the region to the neighbouring civilisations (India, Tibet and China). A major node is thus a very dense point of significance within the network - e.g. with further temples or cave sites in the vicinity (Fig. 2b). It is usually a major cultural centre, a locale where knowledge and cultural techniques of any kind are produced and diffused. As such it creates, absorbs and conveys the spread of knowledge in a given region. A minor node is a cultural centre which primarily serves as a conductor for cultural (and religious) practices that, for the most part, have been produced elsewhere; at times the received practices are slightly added to or modified as well. A characteristic of both types of nodes is that they belong to a network often passing through or traversing several culture zones, as is indeed the case with the oasis towns along the Central Asian trade routes.

When seeking to identify and describe the processes of transmission that take place within a cultural network such as that presented here, there are various models which one may utilise to explain this phenomenon. The BuddhistRoad team intends to establish a model that will encompass several features simultaneously, including the production, transmission, dissemination, reproduction, recurrence and cultural displacement of Buddhist knowledge (Fig. 3). This theoretical model we refer to as a sfeedback loop،, which may be conceived of as an interlocking series of rings, similar to those that appear when droplets fall on the surface of water, with the exception that ripples in water are partly random occurrences, whereas the feedback loops discussed here emanate purposively from the nodes, namely, from concrete geographical and cultural sites. A feedback loop applied to such a context means a movement or wave of influence(s) emanating from one node to another in a circular or recurring fashion (a loop), so that the influence from the original wave comes back to its origin but with something added (the feedback). This added information, which normally comes back in a slightly 
distorted form compared to the original output, has its immediate origin in the second or receiving node, which, for its part, is the product of the interplay between the feedback loops of a whole string of interconnected nodes. As such, the feedback loop can be understood as a primary, engendering force behind a given oscillating process, i.e. a back-and-forth movement of data, material goods, ideas, practices, rituals etc.

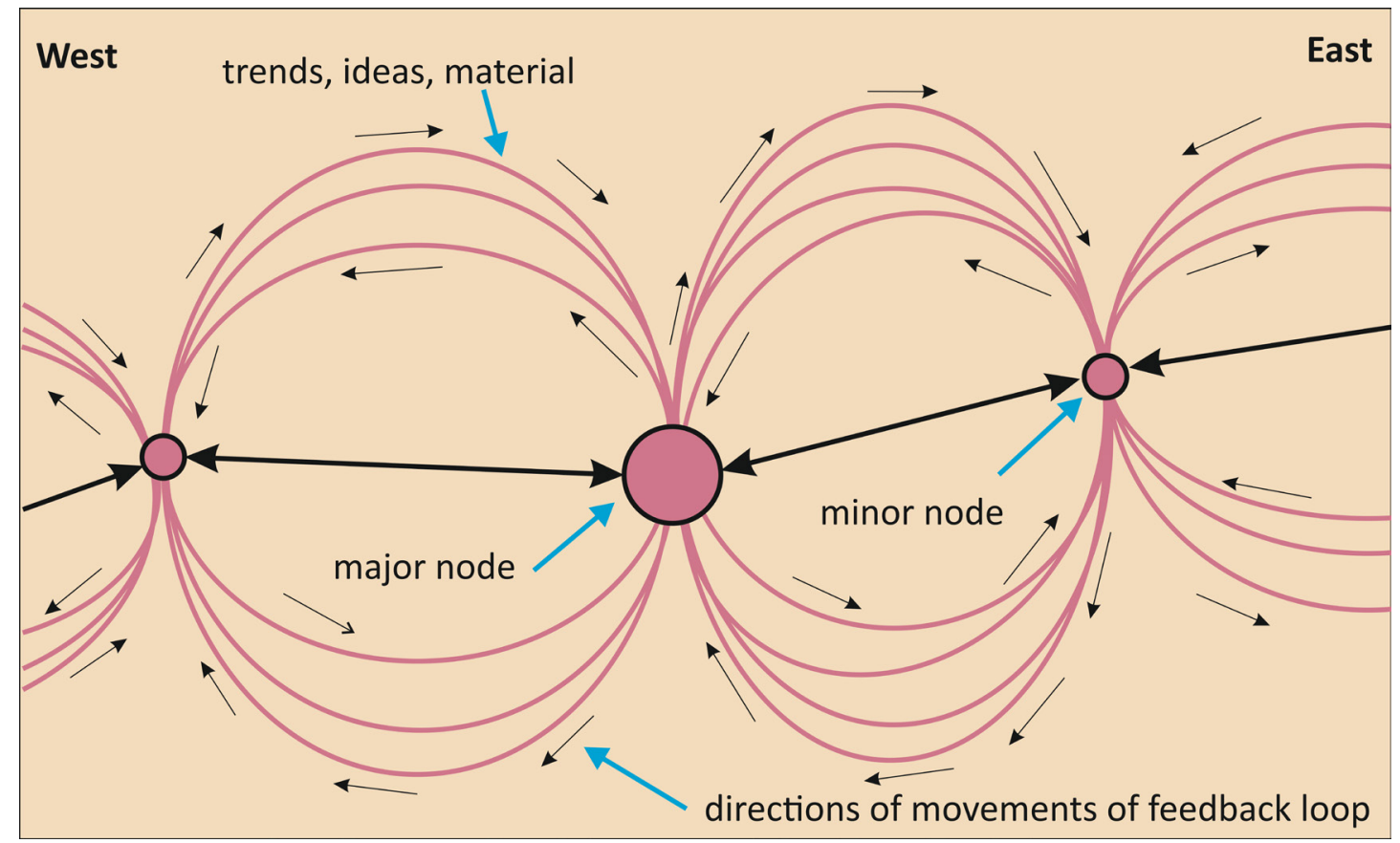

Fig. 3: Buddhist network with model of feedback loop, by BuddhistRoad project

However, when applying this network approach it is crucial to understand that several nodes within a given network may share a common material culture, a set of ideas or ritual technologies, yet these cannot serve as a direct indicator of foreign control or hegemony per se; individuals and groups are rather selective in what they choose to borrow from other groups. In terms of developing a deeper understanding of intercultural contacts, it is not the mere fact of borrowing in itself which is important, but the benefit it entails for the borrower's own cultural and religious system. How are such elements as new (foreign) knowledge used and what is their factual as well as their symbolic importance in the new social, political and religious context at a specific site? How is it reformulated, acted upon or displaced? Local appropriations thus occur as political circumstances which change and shape material culture, whereby ideas or ritual systems become entangled with local politics. In other words, it becomes "a process of local appropriation for local ends. $\aleph^{2}$ Instead of interpreting this process as a simple rdiffusion power, the research programme sketched here favours an approach of actually detecting patterns, processes and motivations.

2 Thomas, Entangled Objects, 184. For a systematic analysis of a new paradigm of interregional interaction see Stein, From Passive Periphery to Active Agents, 905f. 
Thus, the research agenda of the BuddhistRoad project is to look at the correlation between shifting localities and shifting meanings: each specific locality forms its own version of Buddhism based on a mosaic of received elements and local developments, eventually evolving into an independent tradition claiming genuine Indian/Tibetan/Chinese origins.

How do we intend to operationalise this research programme? We envision demonstrating the nature of the Eastern Central Asian transformation process of Buddhism both from the perspectives of local cultures and from a translocal perspective (i.e. Buddhism as a superordinate unifying factor) on the basis of studying primary sources through clusters of case studies. Thematic clusters are chosen for two reasons: (i) they are induced by the materials; (ii) they are aligned according to the following systemic viewpoints: (1) >doctrines are studied to reflect the cognitive side of religion, which gives orientation, whereas (2) rrituals and practices are related to actions that will serve accomplishing objectives; (3) rimpacts of non-Buddhist influences refer to the contact dimension with other religions whereas (4) spatronage and legitimation strategies deal with the contact between religion and politics; and, finally, (5) >sacred spaces and pilgrimages, $<$ and (6) >visual and material transfers concerned with spatial and material aspects of religion.

Over the course of five years, the BuddhistRoad team will organise three conferences (and one summer school) through which to present our research results and discuss them with other scholars (and students) in an interdisciplinary forum. Each of the conferences will focus on two of the above-mentioned thematic clusters: the start-up conference, held in May 23-25, 2018 in Bochum on patronage/legitimation and sacred space/pilgrimage, the second conference to be held in Bochum on September 16-18, 2019 on rituals/practices and visual and material transfer, and a final conference in autumn 2021 on doctrines and non-Buddhist influences.

\section{Religious Patronage and Sacred Space: The BuddhistRoad Start-up Conference, Held in May 23-25, 2018}

The start-up conference held in May 2018 was entitled "Establishing of Buddhist Nodes in Eastern Central Asia 6th to 14th c.-Part I: Sacred Space, Pilgrimage, Patronage, Legitimation Strategies $",{ }^{3}$ a well-received platform for interdisciplinary exchange, where Art Historians, Buddhologists, Sinologists, Tangutologists, Tibetologists, and Turkologists engaged - possibly for the first time - in fruitful discussion, overcoming the boundaries of their own sub-disciplines.

The BuddhistRoad team developed the conference topic on the working hypothesis that for a given religious tradition to flourish to the extent of leaving imprints in all societal fields in a specific geographical region, the establishment of strong patronage systems are of paramount importance. In conceptualizing the dynamics of religious patronage, the BuddhistRoad team established that it takes place between the three societal fields of politics, economics and religion. However, not all patronage activities that take place at the interface of these three fields necessarily entail religious results. We defined religious patronage as

3 The conference programme is provided here: static.ceres.rub.de/media/uploads/2018/04/24/201805-buddhistroadstart-up-conference-web_xYSWEI9.pdf. 
the aspiration for good results, with the achievement of either purely religious results (in the sense of Buddhist merit, the attainment of salvation etc.) or of non-religious results (power, sovereignty, social cohesion of a multicultural society etc.). The latter may also enhance the divine legitimation of a local ruler and, as such, function as one aspect of a broader legitimation strategy. It is only through long-term institutional patronage, supported by occasional private donations, that a cultural region is gradually and thoroughly transformed into a religious-cultural entity - as is visible in the process of Buddhicisation of Eastern Central Asian lands with the establishment of Buddhist sacred sites and pilgrimage routes.

The BuddhistRoad team members engaged in discussing this conceptual framework on the basis of the following case studies:

Carmen Meinert explored the relationship between Tangut imperial patronage of Tibetan Tantric masters, teachings and art and the deliberate creation of a network of Tantric Buddhist sites at the height of the Tangut Empire (ca. 1038-1227) in the late 12th century. Using several items of visual evidence, she showed that the Tangut Emperor Renzong (r. 1139-1193) not only acted in his function as a ruler, perceived as a Buddhist ruler, but also with the personal agenda of a Buddhist initiate. He initiated the production of a new visual imagery in major nodes, which was then also reproduced in minor nodes.

Yukiyo Kasai talked about the legitimation strategy of the Uyghur rulers from the 7th to the 14th century. She illustrated how the religious shift from Manichaeism to Buddhism of the Uyghurs was reflected in the rulers' titles. Moreover, she discussed the relationship between rulers and religious communities. Although the rulers supported religious communities financially, they were not officially visible as donors. This did not change with the establishment of Mongol rule (early 13th c.), but when the Mongol rulers started to strongly promote Buddhism it also affected the Uyghur rulers, who started to show their personal beliefs more openly.

Erika Forte presented a study on pictorial evidence from Khotan to understand the way patronage was expressed in images. This evidence, probably produced around the 7 th/8th centuries, seems to point to a specific way of communicating patronage, notwithstanding the absence of explicit depictions of donors and of inscriptions.

Henrik H. Sørensen gave a presentation on how Esoteric Buddhist imagery appeared in donated paintings by elite members of Dunhuang's society in the 10th century including rulers and the nobility. This shows the intimate relationship between Buddhist practices and beliefs on the one hand, and political power and religion on the other. These votive paintings often feature copious donor inscriptions, in which the giver expresses his or her wishes and prayers on the religious level and, on a more worldly level, signals his or her place in society (Fig. 4). 


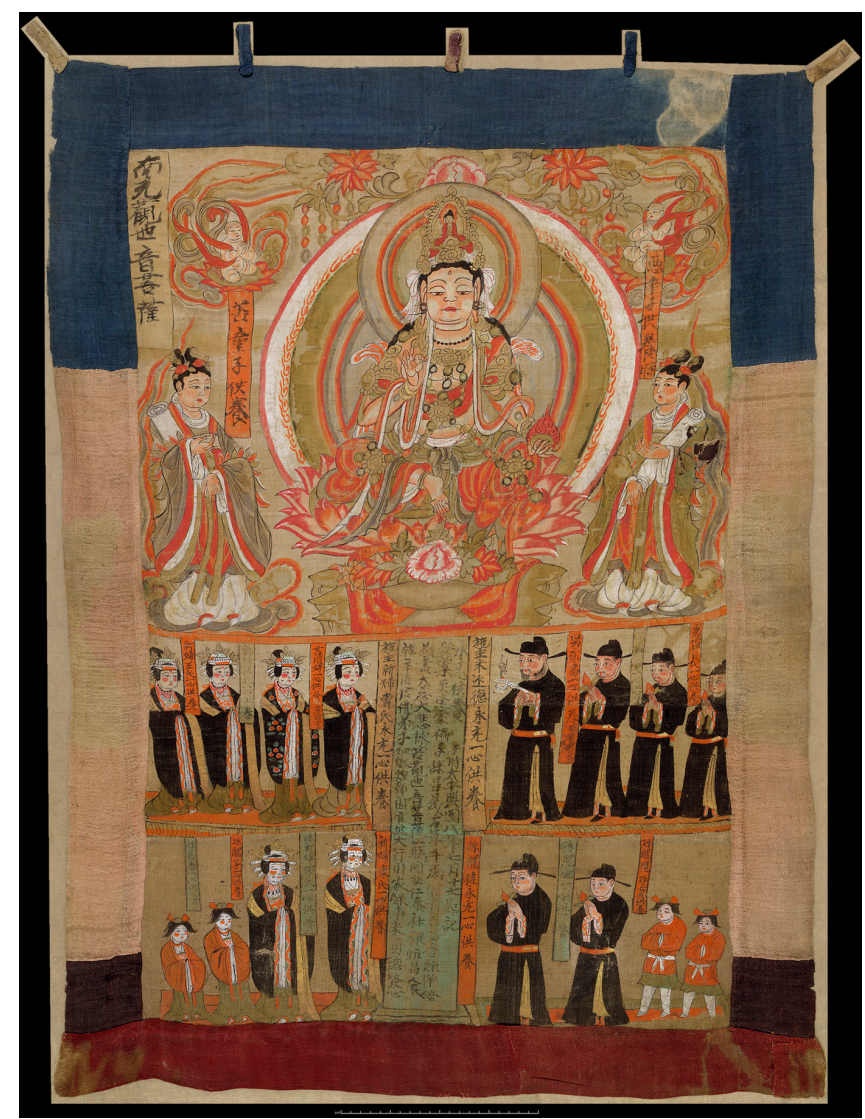

Fig. 4: Avalokiteśvara with donors from the Dunhuang nobility, Dunhuang, 10th century, British Museum, $O A$ $1919,0101,0.54 .^{4}$

\section{Expected Forthcoming Publications}

Part of the BuddhistRoad project's expected outcome is to produce BuddhistRoad Papers, each of which highlights a specific case study or cluster of related cases. These papers are meant to constitute the backbone of the project and demonstrate the extent and direction of ongoing research. Most of the BuddhistRoad Papers already produced, or in the making, reflect presentations by the various members at conferences and workshops. Moreover, the BuddhistRoad team will co-author books, with team members co-authoring a chapter together and thereby covering the six thematic clusters mentioned above. The PI, Carmen Meinert, further aims to sum up the results of the five-year project in a monograph on the history of Central Asian Buddhism and will thereby contribute to the understanding of religious transfer processes in a multi-cultural and multi-religious pre-modern society. ${ }^{5}$

4 ๑ The Trustees of the British Museum. Shared under a Creative Commons Attribution-NonCommercial-ShareAlike 4.0 International (CC BY-NC-SA 4.0) licence.

5 All peer reviewed publications of the BuddhistRoad project including the BuddhistRoad Papers and books will be available open access on the project website: buddhistroad.ceres.rub.de/en/publications/. Moreover, the BuddhistRoad Papers will also be published on the website of the library of Ruhr-Universität Bochum: omp.ub.rub.de/index.php/BuddhistRoad/index. 


\section{Acknowledgements}

The research and writing of this article were facilitated through the BuddhistRoad project which has received funding from the European Research Council (ERC) under the European Union's Horizon 2020 research and innovation programme (grant agreement No 725519).

\section{References}

\section{Secondary literature}

Beckwith, Christopher I., Empires of the Silk Road. A History of Central Eurasia from the Bronze Age to the Present (Princeton, 2009).

Stein, Gil J., From Passive Periphery to Active Agents: Emerging Perspectives in the Archaeology of Interregional Interaction, American Anthropologist 104/3 (2002) 903-916.

Thomas, Nicholas, Entangled Objects (Cambridge, 1991).

\section{List of Figures}

Figure 1: Network of Buddhist nodes in Eastern Central Asia.

Figure $2 \mathrm{a}+\mathrm{b}$ : Buddhist network with (a) model of transmission and (b) major node.

Figure 3: Buddhist network with model of feedback loop.

Figure 4: Avalokiteśvara with donors of Dunhuang nobility, Dunhuang, 10th century, British Museum, OA 1919,0101,0.54 @ The Trustees of the British Museum. Shared under a Creative Commons Attribution-NonCommercial-ShareAlike 4.o International (CC BY-NC-SA 4.0) licence. 